\title{
Determinants of hospital length of stay among patients with pneumonia admitted to a large Canadian hospital from 1991 to 2001
}

\author{
Margaret J McGregor MD MHSc ${ }^{1,2}$, J Mark FitzGerald MD FRCPC 1 , Robert J Reid MD PhD 3 , Adrian R Levy PhD 3 , \\ Michael Schulzer MD PhD ${ }^{1}$, David Jung BSc ${ }^{1}$, Horacio E Groshaus MD MHA ${ }^{1}$, Michelle B Cox MSc ${ }^{1}$
}

\begin{abstract}
MJ McGregor, JM FitzGerald, RJ Reid, et al. Determinants of hospital length of stay among patients with pneumonia admitted to a large Canadian hospital from 1991 to 2001. Can Respir J 2005;12(7):365-370.
\end{abstract}

BACKGROUND: Pneumonia is a common reason for hospital admission, and the cost of treatment is primarily determined by length of stay (LOS).

OBJECTIVES: To explore the changes to and determinants of hospital LOS for patients admitted for the treatment of communityacquired pneumonia over a decade of acute hospital downsizing.

METHODS: Data were extracted from the database of Vancouver General Hospital, Vancouver, British Columbia, on patients admitted with community-acquired pneumonia (International Classification of Diseases, Ninth Revision, Clinical Modification codes 481.xx, 482.xx, 483.xx, 485.xx and 486.xx) from January 1, 1991 to March 31, 2001. The effects of sociodemographic factors, the specialty of the admitting physician (family practice versus specialist), admission from and/or discharge to a long-term care facility (nursing home) and year of admission, adjusted for comorbidity, illness severity measures and other potential confounders were examined. Longitudinal changes in these factors over the 10-year period were also investigated.

RESULTS: The study population $(n=2495)$ had a median age of 73 years, $53 \%$ were male and the median LOS was six days. Adjusted LOS was longer for women (10\% increase, $95 \%$ CI 3 to 16), increasing age group ( $7 \%$ increase, $95 \%$ CI 4 to 10 ), admission under a family physician versus specialist (42\% increase, $95 \%$ CI 32 to 52 ) and admission from home with subsequent discharge to a long-term care facility (75\% increase, $95 \%$ CI 47 to 108). Adjusted hospital LOS decreased by an estimated $2 \%$ (95\% CI 1 to 3 ) per annum. The mean age at admission and the proportion admitted from long-term care facilities both increased significantly over the decade $(\mathrm{P}<0.05)$.

CONCLUSIONS: Results suggest that the management of hospitalized patients with pneumonia changed substantially between 1991 and 2001. The interface of long-term care facilities with acute care would be an important future area to explore potential efficiencies in caring for patients with pneumonia.

Key Words: Community-acquired pneumonia; Hospital downsizing; Long-term care facilities; LOS; Pneumonia admissions

\section{Facteurs déterminants de la durée du séjour à l'hôpital chez des patients admis dans un important centre hospitalier pour une pneumonie, au Canada, entre 1991 et 2001}

CONTEXTE : La pneumonie constitue un motif fréquent d'hospitalisa tion, et le coût du traitement dépend essentiellement de la durée du séjour à l'hôpital.

BUT : Étudier les changements et les facteurs déterminants du séjour à l'hôpital chez des patients admis pour une pneumonie d'origine communautaire (POC), sur une période de 10 ans, période au cours de laquelle il y a eu rationalisation des ressources dans les hôpitaux de soins actifs. MÉTHODE : Les données recueillies provenaient de la base de données du Vancouver General Hospital, à Vancouver, concernant les patients admis pour une POC (codes selon la Classification internationale des maladies, ge version, Modifications cliniques : 481.xx, 482.xx, 483.xx, 485.xx, 486.xx) entre le $1^{\mathrm{er}}$ janvier 1991 et le 31 mars 2001. Nous avons étudié l'effet de différents facteurs, notamment du contexte sociodémographique, de la spécialité du médecin recommandant l'admission (généraliste versus spécialiste), de l'admission depuis les établissements de soins prolongés (centres d'hébergement) ou du renvoi vers ce type d'établissement, de l'année d'admission, des rajustements pour tenir compte des maladies concomitantes, des mesures de gravité de la maladie et d'autres facteurs parasites possibles. Nous avons également passé en revue les variations longitudinales de ces facteurs sur la période de 10 ans.

RÉSULTATS : La population à l'étude ( $\mathrm{n}=2495)$ avait un âge médian de 73 ans; 53 \% des patients étaient des hommes et la durée médiane du séjour était de 6 jours. La durée du séjour rajustée était plus longue pour les femmes (augmentation de $10 \%$; intervalle de confiance [IC] à $95 \%$ : 3 à 16); elle augmentait également en fonction du groupe d'âge (augmentation de $7 \%$; IC à $95 \%$ : 4 à 10), selon que la demande était faite par un généraliste plutôt que par un spécialiste (augmentation de $42 \%$; IC à $95 \%$ : 32 à 52) et que le point de départ était le domicile et le point d'arrivée, un établissement de soins prolongés (augmentation de $75 \%$; IC à $95 \%$ : 47 à 108). La durée du séjour rajustée a diminué d'environ $2 \%$ par année (IC à $95 \%$ : 1 à 3). Nous avons également noté une augmentation significative de l'âge moyen au moment de l'admission et de la proportion de patients admis depuis des établissements de soins prolongés au cours de la période étudiée $(\mathrm{P}<0,05)$. CONCLUSIONS : Les résultats donnent à penser que le traitement des patients hospitalisés pour une pneumonie a changé de façon importante entre 1991 et 2001. L'intervalle entre les établissements de soins prolongés et les établissements de soins actifs devrait faire l'objet d'un examen; il recèle sans doute des possibilités d'efficience dans les soins aux patients atteints d'une pneumonie.

\footnotetext{
${ }^{1}$ Centre for Clinical Epidemiology and Evaluation; ${ }^{2}$ Department of Family Practice, ${ }^{3}$ Department of Health Care and Epidemiology, University of British Columbia, Vancouver, British Columbia

Correspondence: Dr Margaret J McGregor, Centre for Clinical Epidemiology and Evaluation, Room 713, 828 West 10th Street, Vancouver, British Columbia V5Z 1L8. Telephone 604-873-3666, fax 604-875-8790, e-mail mrgret@interchange.ubc.ca
} 
$\mathrm{P}$ neumonia is the second most common reason for hospital admission in developed countries, and the vast majority of the direct costs for treating pneumonia are estimated to result from in-hospital treatment (1); therefore, the costs of treating patients with pneumonia are driven to a large extent by hospital length of stay (LOS). Thus, it is essential to understand the factors associated with hospital LOS for patients admitted with pneumonia.

An extensive body of literature from the United States has examined the costs of treating pneumonia (2), the impact of clinical protocols designed to improve hospital treatment for pneumonia $(3,4)$ and differences in LOS and other outcomes among patients admitted for community-acquired pneumonia (5-10). In Canada, Feagan et al (11) performed a cross-sectional chart review of 858 cases of pneumonia admission to 20 hospitals across the country and found a high variability in compliance with the American Thoracic Society pneumonia treatment guidelines (49\% to $100 \%$ across the hospitals studied), with differences in the duration of intravenous antibiotic therapy up to 3.5 days. Jin et al (12) conducted a population-based study of all hospitalized patients with pneumonia in Alberta over a five-year period and found that urban hospitals had a longer LOS after adjustment for case complexity; however, rural hospitals had more hospital admissions for pneumonia. Carriere et al (13) also examined population data from Alberta and reported that although LOS increased with age, hospital costs of pneumonia decreased with older age due to the more limited therapies offered to those aged over 85 years.

Over the past 15 years, Canadian acute care hospitals have been characterized by a trend toward a decreasing number of acute hospital beds. Statistics Canada (14) reports that between 1990/1991 and 1995/1996, total hospital LOS declined from 41.1 to 35.5 million days, and the mean hospital LOS across Canada for all admissions declined from 11.5 to 11 days. In Vancouver, British Columbia, the number of acute bed days per 1000 population decreased from 676 days in 1994 to 558 days in 1998 (15). The present study explored the determinants of hospital LOS for patients admitted for the treatment of community-acquired pneumonia to a large teaching hospital in Vancouver over a 10-year period of acute hospital downsizing.

\section{OBJECTIVES}

- To determine the factors (sociodemographic, functional health status and service provider factors) associated with hospital LOS among patients with communityacquired pneumonia after adjustment for comorbidity, illness severity and other potential confounders;

- To evaluate whether hospital LOS for patients with pneumonia changed over a 10-year period of hospital downsizing; and

- To determine whether the factors influencing hospital LOS for this patient population changed over a 10-year period.

\section{METHODS}

\section{Study population and setting}

Vancouver General Hospital is a large urban teaching hospital in British Columbia. Discharge data on all hospital admissions are routinely collected by trained coders working in the medical records department. This information is then entered into a database and is subsequently transferred to the Canadian Institute for Health Information. Some data fields (eg, specialty of the most responsible physician) are only available at the hospital level and, therefore, are not transferred to the Canadian Institute for Health Information.

In the present study, hospital level data from the hospital discharge database were used. Administrative data were retrospectively extracted on all patients with a most responsible discharge diagnosis of community-acquired pneumonia (International Classification of Diseases, Ninth Revision, Clinical Modification [ICD-9-CM] [16] codes 481.xx, 482.xx, 483.xx, 485.xx, 486.xx) given from January 1, 1991 to March 31, 2001. Case mix groups (CMGs) for simple pneumonia and pleurisy (CMG143, n=1636), pneumonia with interstitial lung disease (CMG139, n=205), pneumonia with chronic obstructive pulmonary disease (CMG140, $\mathrm{n}=287$ ), pneumonia with pulmonary edema (CMG141, $n=306$ ) and pneumonia with inflammation (CMG137, n=62) were included. Patients whose residence was outside of Vancouver $(n=726)$, those admitted from or transferred to another acute care hospital $(n=146)$, and outlier observations (age younger than 14 years or older than 98 years or LOS greater than 90 days) $(n=13)$ were excluded. Patients discharged to a geriatric step-down unit within the hospital (discharge planning unit) were also excluded because it was not possible to distinguish the separate LOSs between the medical and the geriatric step-down units from the total LOS.

\section{Data items examined}

Demographic factors (age, sex and socioeconomic status [SES]), measures of functional health status (admission from a long-term care facility and admission from home with discharge to a longterm care facility), service provider (family practice versus specialist) and year of admission, adjusted for comorbidity, illness severity and signing out against medical advice were examined. SES was examined by linking case postal codes to income quintiles using the Statistics Canada postal code conversion program $(17,18)$. Individual level comorbidity was measured using the Deyo adaptation of Charlson comorbidities for ICD-9-CM codes $(19,20)$ examining up to 15 diagnoses listed as contributing to hospital stay. Illness severity was measured using the procedural codes for respiratory failure (ICD-9-CM 518.81, 799.1), hypotension or shock (ICD-9-CM458.xx, 758.5x), ventilation greater than $96 \mathrm{~h}$ (ICD-9-CM 96.72) and dialysis (ICD-9-CM 39.95, 54.98) in a manner similar to that of Jin et al (12). Death and readmission to the same hospital for pneumonia within 30 days of discharge were analyzed as further measures of illness severity. The service provider variable was dichotomized to admission under a family physician versus admission under a specialist. Hospital LOS was measured by subtracting the date of discharge from the date of admission in days.

\section{Data analysis}

Five age groups were created ( 15 to 44 years, 45 to 64 years, 65 to 74 years, 75 to 84 years and 85 years or older) and Charlson comorbidities were grouped into zero, one, two, or three or greater comorbidities. Descriptive statistics on the study population were generated and crude mean LOSs by study population characteristics were calculated based on a patient's index of admission over the study population and excluding repeat admissions for pneumonia by the same individual.

MLn software (Multilevel Models Project, Institute of Education, University of London, United Kingdom) was used to develop longitudinal random effects models for univariate and multivariate analyses of the factors associated with hospital LOS. This technique generates a regression curve for all observations on the same 
individual over the entire study period; therefore, all the data from repeat admissions to the hospital for pneumonia were included.

The outcome variable LOS (in days) had a right skewed distribution and, therefore, all comparative analyses were performed on the natural logarithm of LOS. All variables of clinical and theoretical interest were entered into the multilevel model in the following order: demographic factors (age, sex, SES), behavioural factors (signed out against medical advice), measures of functional health status (admission from a long-term care facility, admission from home with discharge to a long-term care facility), measures of illness severity/comorbidity (respiratory failure, hypotension or shock, ventilation greater than $96 \mathrm{~h}$, dialysis, Charlson comorbidities, death and readmission within 30 days), temporal factors (year of admission) and provider factors (admission under a family physician versus a specialist). Variables that were not significant in the multivariate regression were omitted in the final model, with the exception of one (ie, admission from a long-term care facility). Parameters of the model were exponentiated to estimate the multiplicative effect and the corresponding 95\% CIs for factors associated with LOS, adjusted for illness severity, comorbidity and other potential confounders. For variables significantly associated with LOS, any interaction effects of these variables with year of admission were examined to determine whether the impact of these factors had changed over the 10-year period, and the model was assessed for other first order interactions. Finally, age-adjusted regression analysis of significant factors influencing LOS by year was used to evaluate changes over time, excluding repeat visits by the same individual.

A certificate of ethics approval was obtained from the Clinical Research Ethics Board of the University of British Columbia and the Vancouver Hospital and Health Sciences Centre Research Advisory Committee.

\section{RESULTS}

There were 2906 cases that met the study inclusion criteria. Four hundred eleven cases $(14.1 \%)$ were repeat admissions over the study period; thus, the study population consisted of a total of 2495 patients. The mean and median LOS were 8.42 (SD 8.95) and six (range one to 86) days, respectively.

\section{Characteristics of the study group}

Table 1 describes the characteristics of the study population excluding repeat observations of the same individuals $(n=2495)$. The median age was 73 years with a range of 15 to 98 years, and slightly over one-half of the patients were males $(n=1331,53.3 \%)$. The largest number of patients $(n=801,32 \%)$ in the study population had postal codes that corresponded to the first income quintile representing the lowest 20\% of incomes in Vancouver, although a large amount of data was missing for this variable $(n=398,16.0 \%)$. The missing data were mainly due to admissions from a long-term care facility (nursing home), where use of the postal code of residence as a measure of SES is invalid.

Fourteen per cent $(n=354)$ of all patients were admitted from a long-term care facility and only 39 (1.3\%) patients were admitted from home and discharged to a long-term care facility. Three hundred seventeen $(12.7 \%)$ died in hospital and, of these, $36.7 \%$ died within the first $72 \mathrm{~h}$. One-quarter of admitted patients had chronic obstructive pulmonary disease, with the next two most common comorbidities being congestive heart failure $(15.8 \%)$ and diabetes $(12.8 \%)$. Patients had a median Charlson score of one (range 0 to 5 ). Seventy patients $(2.4 \%)$ were readmitted for pneumonia within 30 days of discharge.

\begin{tabular}{|c|c|}
\hline & n (\%) \\
\hline \multicolumn{2}{|l|}{ Age group (years) } \\
\hline $15-44$ & $428(17.2)$ \\
\hline $45-64$ & $393(15.8)$ \\
\hline $65-74$ & $495(19.8)$ \\
\hline $75-84$ & $704(28.2)$ \\
\hline$\geq 85$ & $475(19.0)$ \\
\hline Male & $1331(53.3)$ \\
\hline \multicolumn{2}{|l|}{ Income quintile } \\
\hline 1 & $801(32.1)$ \\
\hline 2 & $460(18.4)$ \\
\hline 3 & $260(10.4)$ \\
\hline 4 & $235(9.4)$ \\
\hline 5 & $341(13.7)$ \\
\hline Signed self out against medical advice & $57(2.5)$ \\
\hline Admitted from a long-term care facility & $354(14.2)$ \\
\hline $\begin{array}{l}\text { Admitted from home and discharged to } \\
\text { a long-term care facility }\end{array}$ & $39(1.3)$ \\
\hline \multicolumn{2}{|l|}{ Number of Charlson comorbidities } \\
\hline 0 & $1103(44.2)$ \\
\hline 1 & $851(34.1)$ \\
\hline 2 & $378(15.2)$ \\
\hline$\geq 3$ & $163(6.5)$ \\
\hline Died & $317(12.7)$ \\
\hline Respiratory failure & $68(2.7)$ \\
\hline Ventilator & $7(0.3)$ \\
\hline Hypotension or shock & $51(2.0)$ \\
\hline Dialysis & $15(0.6)$ \\
\hline Readmitted within 30 days of discharge & $70(2.4)$ \\
\hline Admitted under a specialist & $1603(64.2)$ \\
\hline Admitted under family practice & $892(35.8)$ \\
\hline
\end{tabular}

${ }^{*} n$ is based on the first observation (visit) over the study period

Thirty-six per cent of patients were admitted under the family practice service and the remainder were admitted by specialists, most of whom were general internists.

\section{Factors affecting LOS}

Table 2 describes the crude mean LOS for various factors. Table 3 shows the results of the multivariate regression model with adjustment for significant illness severity/comorbidity measures and for signing out against medical advice. SES, hypotension or shock, and dialysis were not associated with LOS in the multivariate model and were therefore omitted from the model. Hospital LOS among this cohort of patients with pneumonia was $7 \%$ (95\% CI 4 to 10) longer with each increasing age group and $10 \%$ longer (95\% CI 3 to 16) for female admissions.

Admission under family practice (versus specialist) had a $42 \%$ (95\% CI 32 to 52) longer adjusted LOS. Admission from a long-term facility was not significantly associated with LOS. However, admission from home with subsequent discharge to a long-term care facility was associated with a 75\% (95\% CI 47 to 108) longer LOS. This effect also significantly interacted with year (10\% [95\% CI 4 to 17] longer LOS per year across the decade). No other interaction effects were observed. 
TABLE 2

Crude mean hospital length of stay (LOS) for various characteristics of patients admitted for pneumonia to Vancouver General Hospital, Vancouver, British Columbia, from January 1, 1991, to March 31, 2001 ( $n=2495)^{*}$

\begin{tabular}{|c|c|}
\hline Factor & Mean LOS \pm SD \\
\hline \multicolumn{2}{|l|}{ Age group (years) } \\
\hline $15-44$ & $4.94 \pm 4.05$ \\
\hline $45-64$ & $7.40 \pm 7.35$ \\
\hline $65-75$ & $8.02 \pm 7.41$ \\
\hline $75-84$ & $10.19 \pm 10.75$ \\
\hline$\geq 85$ & $10.20 \pm 8.95$ \\
\hline \multicolumn{2}{|l|}{ Sex } \\
\hline Male & $8.14 \pm 9.08$ \\
\hline Female & $8.75 \pm 8.78$ \\
\hline \multicolumn{2}{|l|}{ Income quintile } \\
\hline 1 & $7.77 \pm 8.02$ \\
\hline 2 & $8.91 \pm 9.06$ \\
\hline 3 & $8.28 \pm 8.21$ \\
\hline 4 & $8.69 \pm 10.10$ \\
\hline 5 & $8.13 \pm 8.95$ \\
\hline \multicolumn{2}{|l|}{ Number of Charlson comorbidities } \\
\hline 0 & $6.77 \pm 7.98$ \\
\hline 1 & $8.72 \pm 8.27$ \\
\hline 2 & $11.18 \pm 10.89$ \\
\hline$\geq 3$ & $11.71 \pm 10.70$ \\
\hline \multicolumn{2}{|c|}{ Signed self out against medical advice } \\
\hline No & $8.42 \pm 8.83$ \\
\hline Yes & $3.67 \pm 2.79$ \\
\hline \multicolumn{2}{|c|}{ Admitted from a long-term care facility } \\
\hline No & $8.01 \pm 8.11$ \\
\hline Yes & $10.90 \pm 12.64$ \\
\hline \multicolumn{2}{|c|}{$\begin{array}{l}\text { Admitted from community and discharged } \\
\text { to a long-term care facility }\end{array}$} \\
\hline No & $7.73 \pm 7.43$ \\
\hline Yes & $23.51 \pm 20.05$ \\
\hline \multicolumn{2}{|l|}{ Died } \\
\hline No & $8.31 \pm 8.68$ \\
\hline Yes & $9.22 \pm 10.57$ \\
\hline \multicolumn{2}{|c|}{ Readmitted within 30 days of discharge } \\
\hline No & $8.48 \pm 8.94$ \\
\hline Yes & $11.50 \pm 11.48$ \\
\hline Admitted under internal medicine & $6.91 \pm 6.75$ \\
\hline Admitted under family practice & $11.15 \pm 11.43$ \\
\hline \multicolumn{2}{|l|}{ Year of admission (fiscal year) } \\
\hline $1990^{\dagger}$ & $9.89 \pm 9.24$ \\
\hline 1991 & $9.87 \pm 10.42$ \\
\hline 1992 & $8.69 \pm 6.70$ \\
\hline 1993 & $8.05 \pm 7.14$ \\
\hline 1994 & $7.98 \pm 6.70$ \\
\hline 1995 & $9.20 \pm 8.79$ \\
\hline 1994 & $7.84 \pm 9.01$ \\
\hline 1997 & $7.21 \pm 6.50$ \\
\hline 1998 & $8.19 \pm 9.53$ \\
\hline 1999 & $8.50 \pm 10.50$ \\
\hline 2000 & $9.19 \pm 12.04$ \\
\hline
\end{tabular}

${ }^{*} n$ is based on the first observation (visit) over the study period; †January 1 , 1991, to March 31, 1991 (the final quarter of fiscal year 1990)
TABLE 3

Multiplicative effect in per cent and $95 \% \mathrm{Cl}$ of various factors among patients admitted for pneumonia to Vancouver General Hospital, Vancouver, British Columbia, from January 1, 1991, to March 31, 2001† $\left(n=2661^{\ddagger}\right)^{\S}$

\begin{tabular}{lc}
\hline Factor & Per cent effect $(\mathbf{9 5 \%} \mathrm{Cl})$ \\
\hline Per increasing age group & $7(4 \text { to } 10)^{* *}$ \\
Female & $10(3 \text { to } 16)^{\star *}$ \\
Admitted from home and discharged to & $75(47 \text { to } 108)^{* *}$ \\
$\quad$ a long-term care facility & \\
Admitted from a long-term facility & $2(-8$ to 12$)$ \\
Admitted under family practice & $42(32 \text { to } 52)^{* *}$ \\
Increasing year of admission & $-2(-3 \text { to }-1)^{* *}$
\end{tabular}

${ }^{*} P<0.01 ;{ }^{*} P<0.001 ;{ }^{\dagger}$ Note that the effect is multiplicative due to the logarithmic transformation of the outcome variable in the regression analysis; $\ddagger_{n}$ is smaller than the total sample size $(n=2906)$ due to missing data; 'Estimates have been adjusted for the following covariates: signed self out against medical advice, number of Charlson comorbidities, death, respiratory failure, on ventilation for more than $96 h$ and readmission to the same hospital within 30 days of discharge; TTo fully describe pneumonia admissions from a nursing home setting, this variable, although not significant, was retained in the model

Temporal trends

The number of admissions for pneumonia increased in 1993 with a mean monthly admission rate of 13 patients per month before 1993 and 21 patients per month after that time. No change over time was observed in deaths occurring in hospital, mean number of comorbidities, patients requiring ventilation longer than $96 \mathrm{~h}$ or with respiratory failure. The mean age of admitted patients in the first three years was 67.8 (SD 19.5) years, and in the last three years was 69.6 (SD 18.6) years; age at admission increased significantly over the decade $(\mathrm{P}<0.05)$. A significant increase in admissions from a long-term care facility over time was also observed (age-adjusted $\mathrm{P}<0.05)$, and $16 \%(\mathrm{n}=132)$ of all patients admitted in the last three years of the study came from nursing homes compared with $10 \%$ in the first three years. After adjustment for covariates, increasing year was associated with a $2 \%$ (95\% CI 1 to 3) per year shorter LOS (Table 3), with no significant increase in the number of readmissions to the same hospital.

\section{DISCUSSION}

The median LOS of six days found in the present study is comparable with American and Canadian hospital LOSs for patients with pneumonia over a similar time period $(8,13)$. The finding that adjusted hospital LOS for patients admitted with community-acquired pneumonia decreased by an estimated $20 \%$ between 1991 and early 2001 suggests that the magagement of patients with pneumonia changed significantly over the decade. One factor contributing to this difference may be the advent of macrolide antibiotics and respiratory quinolones, or the introduction of potent oral therapy a priori regimens in the late 1990s, permitting a more rapid switch from intravenous to oral therapy $(21,22)$. It is also possible that some of the observed reduction is the result of administrative pressure on clinicians to discharge earlier, and the use of clinical pathways and guidelines to encourage more timely discharge.

In the present study, the decreased LOS over time, within the context of no apparent change in hospital mortality or readmission to the same hospital within 30 days of discharge, suggests that the observed decrease may reflect a true improvement in efficiency. However, due to limitations of the data, we were unable to examine the rates of readmission of these patients to other hospitals or mortality rates after discharge to confirm that 
outcomes are not affected by the reduction in LOS. The costs to the community, in terms of both formal home care services and informal care provided by friends and family, readmissions to other hospital and postdischarge mortality are all measures requiring further quantification before any conclusions can be drawn about added efficiency through earlier discharge.

The increased number of cases of pneumonia admission after 1993 is likely a result of a 1993 closure of a medium-sized acute hospital located approximately $10 \mathrm{~min}$ away from the study hospital, and a subsequent increase of 93 additional nonintensive care unit medical beds (to a total of 363) at the study hospital $(23,24)$.

The present study found that although men were more often admitted for pneumonia, women had a 10\% longer adjusted LOS. It is known that older women have more disabilities than men (25) and we speculate that the longer adjusted LOS for women may be confounded by inadequate adjustment for disability. Our study (10) found no significant difference in mortality or comorbidity by sex, although previous population-based research in the United States has shown that men admitted to a hospital for pneumonia have greater comorbidity and a higher mortality.

The finding that family practice admissions were associated with an estimated $41 \%$ longer adjusted LOS than for those admitted under specialists could be due to several factors. First, the median age of patients admitted by family physicians was significantly higher (81 versus 67 years) and, like the sex effect, it is possible that resulting differences in function, incompletely measured by the existing data, account for the observed difference. It is also possible that case management by communitybased family physicians is less efficient than case management performed by hospital-based physicians. Community-based practitioners may perform hospital rounds on their patients less often and, thereby, cause a greater delay in discharge planning compared with their hospital-based counterparts. Rifkin et al (9) found that patients with pneumonia admitted under internal medicine hospitalists had significantly shorter LOSs compared with primary care internists due to earlier recognition of stability and more rapid conversion from intravenous to oral antibiotics. Similarly, Stein et al (7) found that patients cared for by hospitalbased generalists working with house staff discharged patients with pneumonia more quickly than community-based physicians working with house staff or alone. With the shift of family practice hospital care to a 'hospitalist' model in most of the larger hospitals over the past five years, it would be important to further explore differences in family physician and specialist hospital management of pneumonia.

Although the unadjusted mean LOS was considerably longer for patients admitted from nursing homes, this association lost significance in the multivariate model, suggesting that the unadjusted difference in LOS was confounded by age, comorbidity and illness severity. The finding of no significant effect on LOS being associated with admission from a longterm care facility suggests that those in residential care can be discharged at the same point in their recovery despite their greater level of functional dependency.

In contrast, the present study found that those admitted from their home and requiring subsequent facility placement have a $75 \%$ longer hospital LOS. This finding supports the observation by many hospital administrators that acute care beds blocked by patients awaiting placement in a nursing home is an important obstacle to efficient patient flow. The finding that this effect increased significantly over the decade also suggests that the timeliness of finding long-term care beds for patients unable to be discharged home as a result of functional dependency has become more difficult over time.

The significant increase in admissions from a long-term care facility over time suggests that it may be useful to review facility protocols for the treatment of pneumonia. Supporting nursing homes to manage acute pneumonia within their facility through the provision of parenteral rehydration and respiratory therapy may be an effective intervention to reduce hospital admissions for this illness. Outcome evaluations for this population treated within a facility compared with their treatment in acute care, including patient and family satisfaction surveys, would be an important future line of research.

The present study found no changes in comorbidity or other measures of illness severity (respiratory failure and ventilation longer than $96 \mathrm{~h}$ ) over time. However, the fact that both age and the proportion of admissions from a long-term care facility have increased significantly over time suggests greater frailty and disability among patients admitted for pneumonia now than a decade ago.

\section{Limitations and contributions}

The present study was limited by its reliance on retrospective administrative data from one large urban hospital. As with all retrospective studies, there is the possibility of bias due to misclassification and missing data, and previous research has documented the tendency of discharge data to underestimate comorbidity (26). It should also be noted that the functional measures used in the present study (admission from and discharge to a long-term care facility) captured only the most severe level of disability, ie, institutionalization as a marker of disability, and we were unable to examine less severe markers of disability that may have also had an impact on LOS.

However, both the examination of 10 years of data and the use of hospital level fields allowed for a more detailed analysis of factors influencing LOS over a period of considerable change, thereby contributing to the relatively sparse Canadian literature on this topic.

\section{CONCLUSIONS}

We have shown a significant reduction in the LOS for patients with pneumonia admitted to a large urban hospital in the 1990s. We have identified several factors associated with prolonged hospital LOS and identified the interface between long-term care facilities and acute hospitals as a potential area of focus in reducing hospitalization for pneumonia. The impact of hospitalists compared with community-based physicians on LOS for pneumonia also warrants further study.

ACKNOWLEDGEMENTS: We gratefully acknowledge the assistance of the following individuals: Mr Edwin Mak, who assisted with programming the data; Susan Sirrett and Diane Lofthouse from VGH QUIST, who assisted in data extraction from the VGH database; and Kimberlyn McGrail, who assisted with data linkage of postal codes to income quintiles.

FUDNING: This study was funded by a grant from the Vancouver Foundation FY2002-2003. Dr McGregor is a Vancouver Foundation Community-Based Clinician Investigator. Dr FitzGerald is a British Columbia Lung CIHR Clinical Investigator and a Michael Smith Foundation for Health Research Distinguished Scholar. Adrian Levy is a CIHR New Investigator and a Michael Smith Foundation for Health Research Scholar. 


\section{REFERENCES}

1. Guest JF, Morris A. Community-acquired pneumonia: The annual cost to the National Health Service in the UK. Eur Respir J 1997;10:1530-4.

2. Niederman MS, McCombs JS, Unger AN, Kumar A, Popovian R. The cost of treating community-acquired pneumonia. Clin Ther 1998;20:820-37.

3. Benenson R, Magalski A, Cavanaugh S, Williams E. Effects of a pneumonia clinical pathway on time to antibiotic treatment, length of stay, and mortality. Acad Emerg Med 1999;6:1243-8.

4. Murphy M, Noetscher C, Lagoe R. A multihospital effort to reduce inpatient lengths of stay for pneumonia. J Nurs Care Qual 1999;13:11-23.

5. Halm EA, Fine MJ, Kapoor WN, Singer DE, Marrie TJ, Siu AL. Instability on hospital discharge and the risk of adverse outcomes in patients with pneumonia. Arch Intern Med 2002;162:1278-84.

6. Fine MJ, Medsger AR, Stone RA, et al. The hospital discharge decision for patients with community-acquired pneumonia. Results from the Pneumonia Patient Outcomes Research Team cohort study. Arch Intern Med 1997;157:47-56.

7. Stein MD, Hanson S, Tammaro D, Hanna L, Most AS. Economic effects of community versus hospital-based faculty pneumonia care. J Gen Intern Med 1998;13:774-7.

8. McCormick D, Fine MJ, Coley CM, et al. Variation in length of hospital stay in patients with community-acquired pneumonia: Are shorter stays associated with worse medical outcomes? Am J Med 1999;107:5-12.

9. Rifkin WD, Conner D, Silver A, Eichorn A. Comparison of processes and outcomes of pneumonia care between hospitalists and community-based primary care physicians. Mayo Clin Proc 2002;77:1053-8.

10. Kaplan V, Angus DC, Griffin MF, Clermont G, Scott Watson R, Linde-Zwirble WT. Hospitalized community-acquired pneumonia in the elderly: Age- and sex-related patterns of care and outcome in the United States. Am J Respir Crit Care Med 2002;165:766-72.

11. Feagan BG, Marrie TJ, Lau CY, Wheeler SL, Wong CJ, Vandervoort MK. Treatment and outcomes of community-acquired pneumonia at Canadian hospitals. CMAJ 2000;162:1415-20.

12. Jin Y, Marrie TJ, Carriere KC, et al. Variation in management of community-acquired pneumonia requiring admission to Alberta, Canada hospitals. Epidemiol Infect 2003;130:41-51.
13. Carriere KC, Jin Y, Marrie TJ, Predy G, Johnson DH. Outcomes and costs among seniors requiring hospitalization for community-acquired pneumonia in Alberta. J Am Geriatr Soc 2004;52:31-8.

14. Statistics Canada: Statistical Report on the Health of Canadians, 1999:116.

15. British Columbia Ministry of Health. PURRFECT Population Utilization Rates and Referral for Easy Comparative Tables. (CD-ROM). Victoria, British Columbia, 1999.

16. World Health Organization. International Classification of Diseases, Ninth Revision, Clinical Modification. Geneva, 1977.

17. Wilkins R. Use of postal codes and addresses in the analysis of health data. Health Rep 1993;5:157-77.

18. Wilkins R. PCCF+ version 4D user's guide. Automated geographic coding based on the Statistics Canada postal code conversion files, including postal codes to December 2003. Ottawa: Health Analysis and Measurement Group, Statistics Canada, 2004.

19. Charlson ME, Pompei P, Ales KL, MacKenzie CR. A new method of classifying prognostic comorbidity in longitudinal studies: Development and validation. J Chron Dis 1987;40:373-83.

20. Deyo RA, Cherkin DC, Ciol MA. Adapting a clinical comorbidity index for use with ICD-9-CM administrative databases. J Clin Epidemiol 1992;45:613-9.

21. Chan R, Hemeryck L, O'Regan M, Clancy L, Feely J. Oral versus intravenous antibiotics for community acquired lower respiratory tract infection in a general hospital: Open, randomised controlled trial. BMJ 1995;310:1360-2.

22. Ramirez JA, Vargas S, Ritter GW, et al. Early switch from intravenous to oral antibiotics and early hospital discharge: A prospective observational study of 200 consecutive patients with communityacquired pneumonia. Arch Intern Med 1999;159:2449-54.

23. Canadian Healthcare Association. Guide to Canadian healthcare facilities. Ottawa: CHA Press, 1993-1994.

24. Canadian Healthcare Association. Canadian hospital directory 1992-1993. Ottawa: The Association, 1993.

25. Newman AB, Brach JS. Gender gap in longevity and disability in older persons. Epidemiol Rev 2001;23:343-50.

26. Levy AR, Tamblyn RM, Fitchett D, McLeod PJ, Hanley JA. Coding accuracy of discharge data for elderly survivors of myocardial infarction. Can J Cardiol 1999;15:1277-82. 


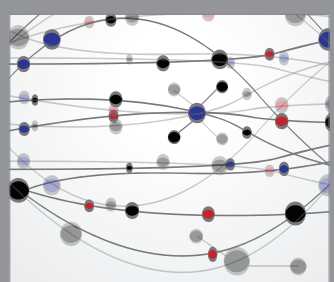

The Scientific World Journal
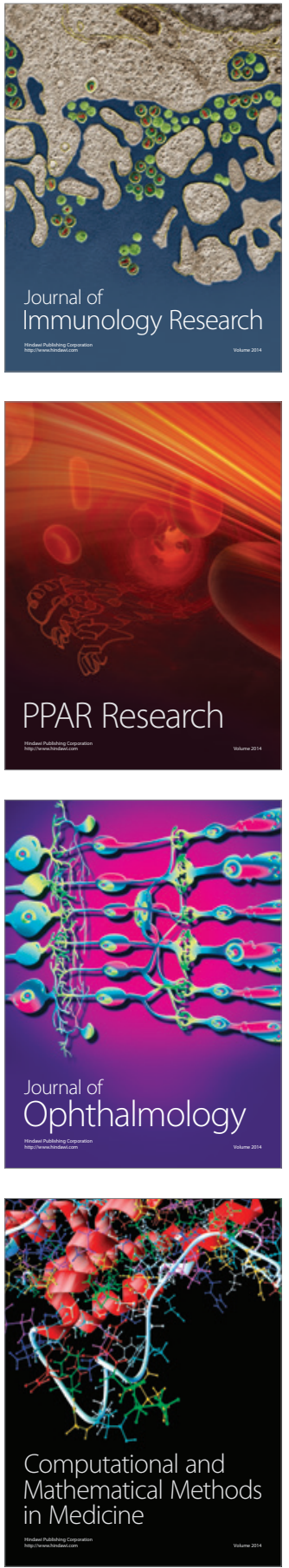

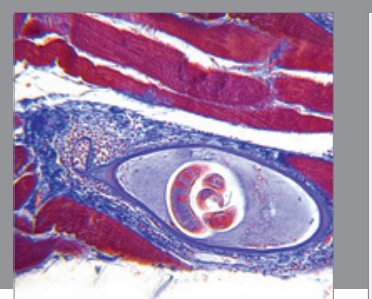

Gastroenterology Research and Practice

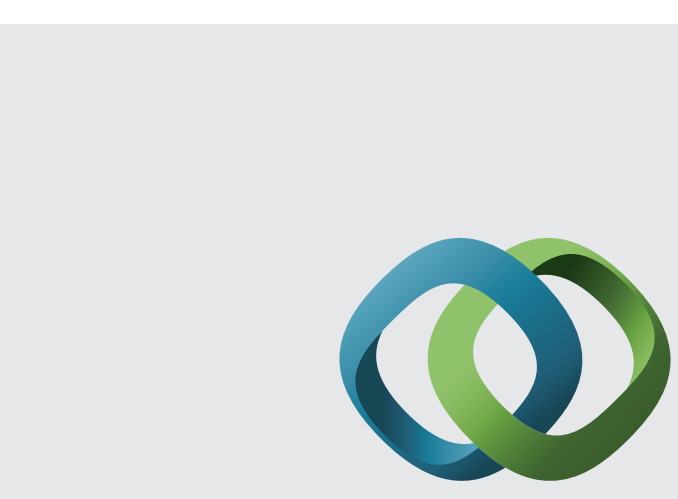

\section{Hindawi}

Submit your manuscripts at

http://www.hindawi.com
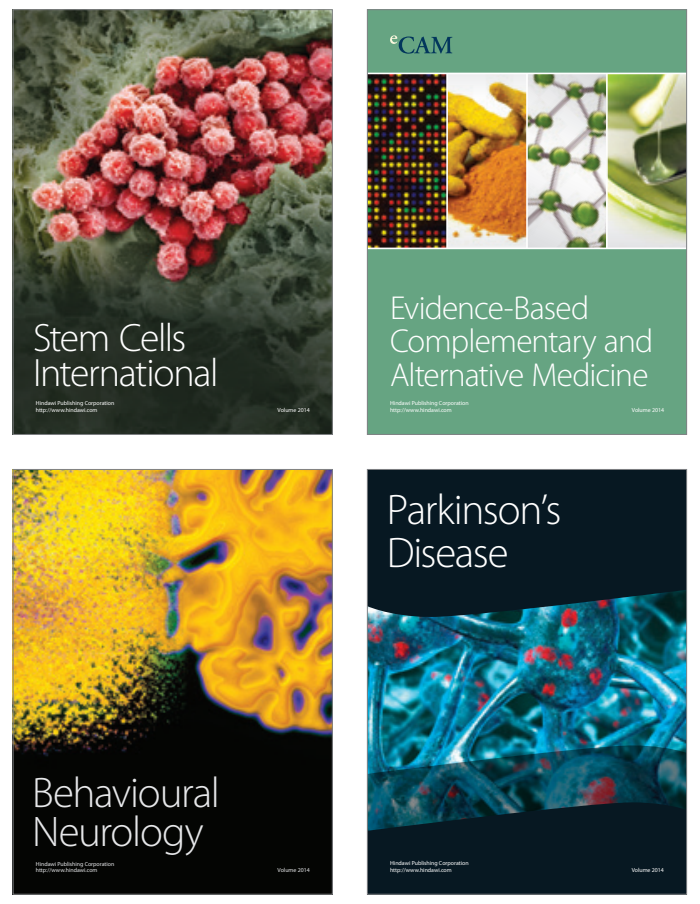
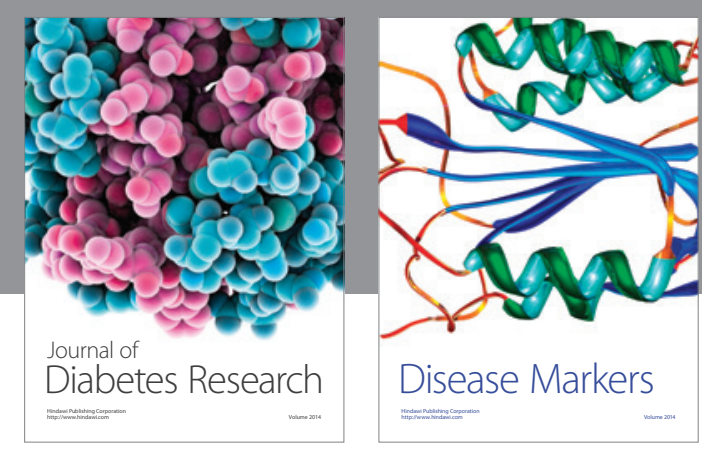

Disease Markers
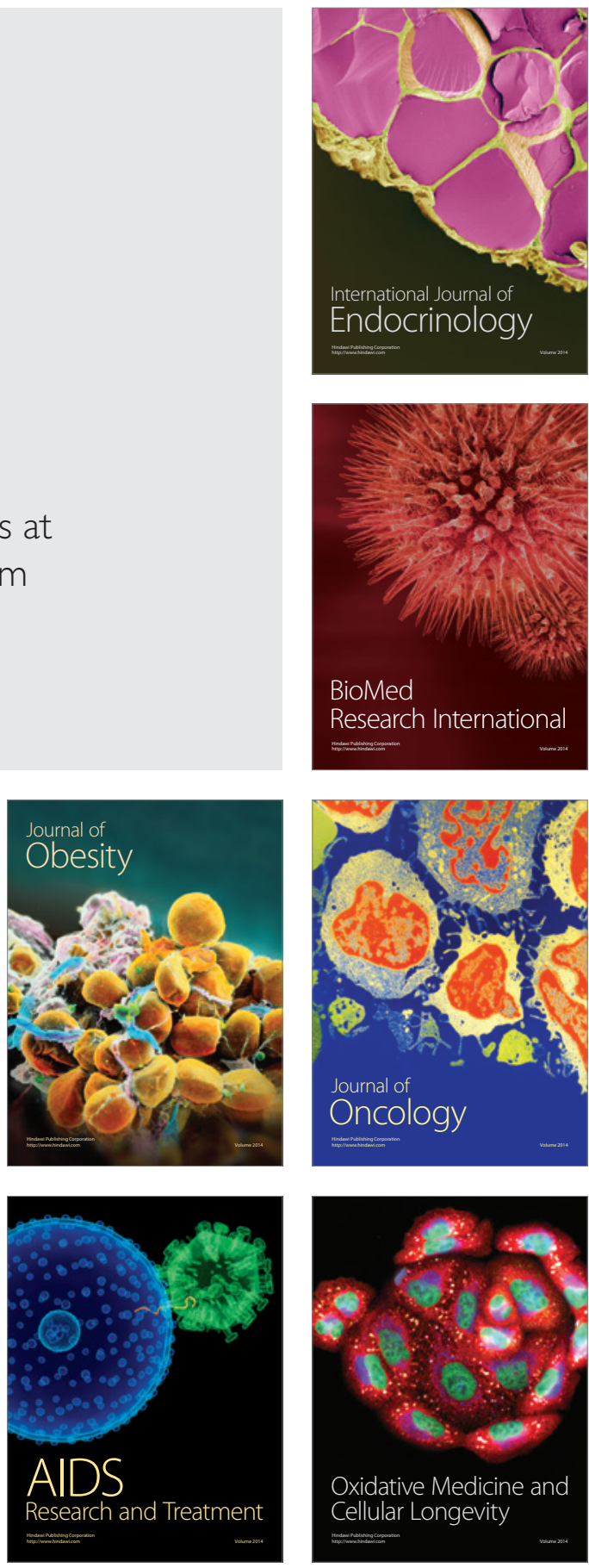